\title{
DISPOSAL CRITICALITY ANALYSIS FOR IMMOBILIZED PLUTONIUM: INTERNAL CONFIGURATIONS
}

MOL .19990326 .0256

\author{
Peter Gottlieb \\ TRW \\ Framatome Cogema Fuels \\ Paul L. Cloke \\ Paul L \\ Civilian Radioactive Waste Management System, Management and Operating Contractor \\ 1180 Town Center Drive \\ Las Vegas, NV 89134
}

\begin{abstract}
The preliminary concepts of plutonium (Pu) immobilization, which included both glass and ceramic waste forms (WF), have been evaluated with respect to disposal criticality. Since the disposal criticality control technique has the neutron absorbing elements contained in the WF itself, both the fissile and the absorber would be available for removal from the waste package (WP) if water drips into the WP, degrading the WF and releasing both the fissile material $\left({ }^{239} \mathrm{Pu}\right.$ or its decay product ${ }^{235} \mathrm{U}$ ) and the neutron absorbers. As the dripping water circulates through, and flows out of, the WP any soluble neutron absorber or fissile material may be removed. Criticality $\left(k_{e f t}\right)$ will be determined by the balance between the amounts of fissile material and neutron absorber that remain in the WP.

A low pH (less than 6.0 , which could occur during the period when stainless steel is corroding) may permit the principal added neutron absorber, $\mathrm{Gd}$, to have at least 1000 times the solubility of $U$ or Pu. Under moderate to high flow rates, this difference in solubility could result in so much of the Gd being removed from the WP, that there could be a criticality. It is shown that appropriate combinations of the following measures can completely preclude the possibility of criticality from these conditions: (1) Limitation on the amount of Pu loaded per waste package; (2) Modification of the WF to lower the dissolution rate; (3) Addition of neutron absorbers which are insoluble over a broad $\mathrm{pH}$ range.
\end{abstract}

\section{Introduction}

Preliminary concepts of plutonium $(\mathrm{Pu})$ immobilization considered both glass and ceramic waste forms (WF). These waste forms were to contain $10 \%{ }^{239} \mathrm{Pu}$, with an equimolar amount of the neutron absorber $\mathrm{Gd}$ as $\mathrm{Gd}_{2} \mathrm{O}_{3}$ for criticality control. This Pu containing matrix was to be carried in $3 \mathrm{~mm}$ thick steel cans, with 20 such cans placed inside a $1 \mathrm{~cm}$ thick cylindrical steel pour canister having the same shape and material as that planned for high level waste
(HLW) glass disposal (Ref. 1). This gives a total of $51.2 \mathrm{~kg}$ of $\mathrm{Pu}\left(93 \%{ }^{239} \mathrm{Pu}\right)$. The remaining $75 \%$ of the pour canister would be filled with defense high level waste (DHLW) glass. One, or two, such Pu containing canisters would then be placed inside a disposal container together with canisters containing only HLW glass. Such a co-disposal waste package (WP) would contain a total of 4 or 5 canisters in a steel cylinder approximately 3.5 meters long with a 1.7 meter inside diameter.

For reference purposes, it should be noted that the current Pu immobilization concept follows the same can-in-can design as the initial concepts described in the previous paragraph, but with only $28 \mathrm{~kg}$ of Pu per canister. Furthermore, the current waste form design incorporates a significant additional amount of the highly insoluble neutron absorber hafnium (Hf) for supplementary, redundant criticality control. This paper summarizes the design guidance developed from the criticality evaluation of the preliminary concepts, and relates that guidance to the evolution from the preliminary concepts to the current design.

The disposal criticality control for all of the waste form concepts that contain immobilized plutonium is characterized by the neutron absorbing elements being contained in the waste form itself. Therefore, both the fissile and neutron absorber materials would be available for removal from the waste package if water drips into the WP, degrading the waste form and releasing both the fissile material $\left({ }^{239} \mathrm{Pu}\right.$ or $\left.{ }^{235} \mathrm{U}\right)$ and neutron absorber. In general, by the time enough of the WF has degraded to permit criticality, most of the ${ }^{239} \mathrm{Pu}$ has decayed into ${ }^{235} \mathrm{U}$. This is an important distinction because $U$ is much more soluble than $\mathrm{Pu}$ and ${ }^{235} \mathrm{U}$ is somewhat less reactive with respect to criticality than is ${ }^{239} \mathrm{Pu}$.

As the dripping water circulates through, and flows out of, the waste package any soluble neutron absorber or fissile material may be removed from the WP. The criticality $\left(k_{\text {eff }}\right)$ of the waste package will be determined by the balance 
between the amounts of fissile material and neutron absorber that remain in the WP. As a convenient shorthand these elements, ${ }^{239} \mathrm{Pu},{ }^{233} \mathrm{U}$, and $\mathrm{Gd}$, will be referred to as neutronically significant elements (NSE), when referring to solubility issues. Although hafnium and iron are also significant neutron absorbers, and are therefore tracked and included in all criticality calculations, they are relatively insoluble, so their removal from the waste package is not a significant analysis issue.

The objective of this study is to systematically evaluate the immobilized Pu waste forms with respect to disposal criticality requirements. To accomplish this objective, the study must determine the circumstances (if any) under which sufficient neutron absorber can be removed from the waste package, or at least separated from the fissile material. Therefore, the balance between the amounts of fissile and neutron absorber materials remaining in the waste package, and in proximity, must be tracked by geochemical analysis. Then, the criticality of this remaining material can be evaluated. If criticality is found, the related analysis can provide guidance for the design of additional waste form criticality control.

The specific purpose of this paper is to summarize the criticality evaluations of the preliminary concepts for glass and ceramic immobilization of plutonium. The results are developed in sufficient generality to suggest design guidelines, and the further evolution of the waste form concepts based on these guidelines is also indicated. Further details of the results for the preliminary immobilization concepts are given in Ref. 1 , which also contains backup analysis relating to the results stated here.

\section{General Approach}

This study follows the degraded mode, disposal criticality analysis methodology (described in more detail in Ref. 2) that has already been applied to other waste forms. This methodology consists of the following steps:

1. From the list of standard degradation scenarios, select those appropriate to this waste form. A degradation scenario is comprised of a combination of features (geologic), events, and processes (physical and geochemical), that result in degraded configurations to be evaluated for criticality.

2. From the list of configuration classes that are derived from the scenarios selected according to the above step, select configuration classes most appropriate to this waste from. A configuration class is defined as a set of similar configurations whose composition and geometry are defined by specific parameters that may vary over a given range.

3. Apply the geochemistry methodology/model to determine compositions (solid and solution) of degradation product materials in the waste package, with particular emphasis on what gets flushed out. It is these compositions which determine the configuration parameters.

4. Calculate $k_{\text {eff }}$ for the potentially critical configurations, using the industry standard Monte Carlo code, MCNP.

5. Develop a mass-balance program to track the amounts of NSE and to compute the $k_{\text {eff }}$ as a function of time, abstracting from the results of steps 4 and 5 , above.

6. Identify the need for, and evaluate, criticality control design improvements.

\section{Appropriate Degradation Scenarios and Configuration Classes}

There are two general scenarios appropriate to the evaluation of the immobilized Pu with respect to internal criticality; both start with penetration of the waste package by dripping water. The first scenario has the waste package penetrated only near the top; in this scenario the water circulates through the waste package (driven by a thermal gradient from the remaining radioactive material) and carries dissolved material out near the top of the waste package; the water in the package may serve as moderator for a criticality. The second scenario has the waste package penetrated at the bottom, as well as at the top, leaving no standing water in the waste package. In this scenario the only source of water for moderation is what can be incorporated in the clay that is formed as the glass degrades. It is assumed that penetrations in the bottom of the waste package will not be large enough to permit the highly viscous clay to flow through. Since the first scenario is much less likely (requiring that the WP bottom remain unpenetrated long after the WP top has been penetrated), and the second scenario is more conservative (since it provides faster removal of the WF degradation products, particularly the neutron absrober), only the second scenario will be evaluated here.

If either scenario is to lead to criticality, it must finish with the removal of $\mathrm{Gd}$ from the WP by flushing as quickly as it is released from the degrading WF. This will happen if the $\mathrm{pH}$ is low enough that the $\mathrm{Gd}$ solubility is relatively high. If the solubility of $\mathrm{Gd}$ is not high enough that its rate of flushing from the waste package is greater than its rate of release from the degrading waste form, the unflushed $\mathrm{Gd}$ will precipitate. However, it can be re-dissolved if (and when) the $\mathrm{pH}$ drops sufficiently that the flush rate exceeds the release rate from the dissolving waste form, or if the solution is still slightly acidic after all the waste form has degraded (a very unlikely condition). Under such conditions, criticality is simply delayed until the removal rate can catch up with the release rate and reduce the $\mathrm{Gd}$ in the precipitate to the point where the remaining fissile material is sufficient for criticality. 
From the above scenario analysis, the principal configuration that can lead to criticality within the waste package has clayey material filling somewhat more than half the waste package, with the fissile material and gadolinium distributed throughout its volume. A set of alternatives, in which the fissile material and $\mathrm{Gd}$ are concentrated in one part of the clayey material, has also been evaluated. These cases are characterized by concentration in one of the following three locations with respect to the basic hemi-cylinder of clayey material: (1) at the top, (2) at the bottom, (3) at one end. All of these scenarios and configurations assume that the clayey material is insoluble; this assumption is supported by experimental data. It is also conservative with respect to internal criticality, since the removal of clay will prevent the accumulation of water required for moderation.

\section{Geochemistry Methodology}

The internal geochemistry model consists of the geochemistry code, EQ6 (the non-equilibrium part of the industry standard geochemistry code, EQ3/6, Ref. 3), plus special software to chain together a sequence of runs (transforming the output of one run into the input for the next run) to create a "pseudo flow through" mode. The calculations were performed for a unit mass of solution, typically 1 kilogram, within the waste package. Amounts of reactants to be input for this unit mass are determined by scaling the total waste package inventory according to the amount of water actually expected to be in the waste package (as a function of time); the results of the calculation are re-scaled back to waste package totals. Reactants are of two types: (1) initial amounts of solute for each dissolved species, and (2) reagents which are added continuously (actually in discrete increments at each time-step), primarily to simulate the elements which can go into solution as the WP internal components degrade. It should be noted that the EQ6 code has recently been modified to accomplish this flow-through modeling directly within the code itself, which will permit a simpler calculation process than that described above.

To simulate the steady dripping of water into the WP, water was also treated as a reagent enfering the reaction at the groundwater drip rate (expressed in $\mathrm{mm} / \mathrm{yr}$ ) averaged over the waste package cross-section area and normalized to the unit volume basis used by EQ6; this rate was simulated by a fixed increment of water at each time-step. Since EQ6 did not have the capability to remove the added water, it would build up over a sequence of time-steps. The removal of water was simulated by restarting the program with the total volume of water reduced to the original amount (e.g., 1 kilogram); the amounts of solids (precipitates) remain the same as at the end of the previous run, but the amounts of solutes (dissolved species) were adjusted downward so that their concentrations in the reduced water volume were the same as they were at the end of the previous run. (As mentioned in the previous paragraph, the flow-through mode has now been incorporated directly into the EQ6 code, so the removal of the water is automatic.) The difference between the solute amounts before and after the restart (or rollover) determines the amount of each species removed from the waste package, and becomes the source term for the external geochemistry.

The output of the internal geochemistry model includes concentrations of solutes and amounts and chemical composition of solid precipitates in the waste package. The successive runs provide these results as a function of time over simulated periods that may be as long as several hundred thousand years. Of particular importance are the amounts of fissile materials and neutron absorbers, both in solution and solids.

The internal geochemistry model is nominally run with constant degradation rates for the solid components, and under the assumption that the degradation products for all these components feed into the same solution which is well mixed on a geologic time scale. In this process, upwards of 100 species are considered simultaneously. Additional cases involving only subsets of the degrading components are used to test the sensitivity to this assumption. It should also be noted that this methodology is applicable to both of the waste package flushing schemes: circulation in a nearly filled waste package, and direct flow-through of a waste package with penetration on the bottom.

A specially-developed mass-balance program uses a pH dependent solubility model for the NSE, which is abstracted from the EQ6 runs. The program computes the amounts of $\mathrm{Pu}, \mathrm{U}, \mathrm{Gd}$, and $\mathrm{Cr}$ in solution as a function of time, and uses the $\mathrm{Cr}$ in solution to estimate the $\mathrm{pH}$. The principal inputs for this code are possible waste-form dissolution rates and stainless steel corrosion rates. The mass-balance program is required to track the individual isotopes of uranium, and to model the radioactive decay of ${ }^{239} \mathrm{Pu}$ into ${ }^{235} \mathrm{U}$. The frequently mentioned possibility of transport of $\mathrm{Pu}$ in colloidal form was not considered in this study, because it would not be conservative, since its effect would be to remove Pu from the waste package.

\section{Application of Geochemistry Methodology}

The principal physical/chemical transformations in the degradation of the waste package internals are the following: (1) dissolution of the DHLW glass, with subsequent formation of clay; (2) dissolution of the $\mathrm{Pu}$ waste form, leaving an altered layer containing the insoluble elements. A major objective of the geochemistry methodology, therefore, is to determine the solubility of each of the elements of the waste form. These solubilities 
are used, together with the drip rate, to determine the amounts flushed out of the WP as a function of time.

The configuration for the ceramic is assumed to be that described for the Pu glass and the generation scenario is also assumed to be the same. The majority of the DHLW glass would be expected to have degraded prior to the degradation of the ceramic material due to the fact that it is exposed first and has a degradation rate significantly higher than that of the Pu ceramic material. The DHLW glass will have degraded into clayey material and other minerals which have slumped to the bottom of the package, along with any remaining pieces of the DHLW glass canisters and the degraded ceramic canisters and WFs. It has been assumed that the ceramic material at this point in time will have undergone considerable metamictization and disintegrated into small particles which are dispersed into the clayey material. Both the bulk, early in time, and the particulate ceramic material, later in time, will be slowly dissolving. The $\mathrm{Pu}, \mathrm{U}$ and $\mathrm{Gd}$ released into solution will either precipitate as other mineral phases or remain in solution, depending on the system $\mathrm{pH}$ and chemistry. These mineral phases will precipitate back onto the particles as an altered outer layer or onto the clayey material to become part of its internal matrix.

Experiments show that $\mathrm{Gd}$ is insoluble under neutral to alkaline conditions and that under acid conditions it goes into solution (Reference 26 of Ref. 1). It is known that conditions as acidic as $\mathrm{pH} 4$ to 5 develop in pits and crevices during corrosion of these metals. It is conjectured that some acidity may result from the corrosion process in stainless steel, which can lead to the oxidation of chromium . to the +6 valence state so that it forms the chromate ion, which produces chromic acid. It remains unknown, however, whether such reactions will occur on a sufficiently broad scale, or rapidly enough, to lower the $\mathrm{pH}$ of an initially strongly alkaline solution to below 6 . For example, the mineral, eskolaite, $\mathrm{Cr}_{2} \mathrm{O}_{3}$, is known to occur "as a major constituent of black pebbles in the bed of the Merume River, Guyana." (Reference 25, p. 197 of Ref. 1), thus demonstrating that $\mathrm{Cr}$ oxide may survive for long times without converting to the higher oxidation state necessary to support acid conditions. Notwithstanding this reservation, the assumption of complete oxidation is used because it is conservative with respect to criticality since the result is removal of $\mathrm{Gd}$ while leaving fissile material behind.

The EQ6 calculations predict that complete degradation of all the DHLW glass in a waste package will ultimately produce 8 to 10 metric tons of clayey material. The precise composition of this clayey material will depend on the relative rates of degradation of the DHLW glass, the steel canisters, and the waste form. The largest component will be oxygen at over $35 \mathrm{wt} \%$. Iron and silicon will be in the 10 to $20 \mathrm{wt} \%$ range. Sodium, potassium, aluminum, and nickel will be in the $1 \%$ to $10 \%$ range. The principal contribution to the clayey material from the ceramic waste form will be plutonium, uranium, gadolinium, hafnium and titanium in the $0.1 \%$ to $2 \%$ range. The average density of the clayey material will be approximately $3.0 \mathrm{~g} / \mathrm{cm}^{3}$. This high value arises from the high content of iron oxides from the corrosion of the steel. The relative amounts of gadolinium and fissile material (uranium and plutonium) remaining in the waste package will be strongly dependant on the $\mathrm{pH}$ history of the waste package chemistry. The solubility of uranium in its $\mathrm{UO}_{2}$ form has its minimum in the near-neutral $\mathrm{pH}$ region, approximately $0.002 \mathrm{ppm}$ over the $\mathrm{pH}$ range 5.8 to 7.4. The solubility of plutonium is, of course, much lower. Gadolinium in its $\mathrm{Gd}_{2} \mathrm{O}_{3}$ form has a solubility minimum of $0.04 \mathrm{ppm}$ near $\mathrm{pH}=7.4$, but increases rapidly as $\mathrm{pH}$ drops below this value, so that it is $10 \mathrm{ppm}$ at $\mathrm{pH}=5.8$. At such a high concentration, most of the gadolinium would be flushed from the waste package rather than trapped in the clay with the fissile material. The mass-balance program is used to determine whether this condition might occur.

The degree of fracturing of the waste form is expressed by a fracture factor; this is defined as the entire surface area (including internal fracture area) divided by the external surface area. A typical fracture factor for the ceramic waste form might be 30 , and for the glass waste form it might be over 100. If it is assumed that all the internal fracture surface is exposed to the same degree of aqueous attack as the external surface, the waste form looks like an aggregation of small particles, which will lose mass in the degradation process at a rate proportional to the remaining surface area. If the particles are approximated as spheres, the rate of WF mass loss will be proportional to the $2 / 3$ power of the remaining WF mass.

Since the stainless steel is mostly in the form of thin $(1 \mathrm{~cm})$, cylindrical shells, the surface area, and consequently the dissolution rate, is constant until most of the steel has degraded, so in this approximation the dissolution rate has been left constant. At the nominal stainless steel dissolution rate of $0.1 \mathrm{~mm} /$ thousand years, the $1 \mathrm{~cm}$ thick canister shells will last 50,000 years if attacked from both sides. If the waste package bottom has been breached so that the water flows directly through the waste package, the canister shells will most likely be attacked from only one side at a time, and the shell continue to corrode for 100,000 years. The WF will typically last longer.

During the period that the WF is degrading, insoluble fissile isotopes will precipitate into the clayey material. If the $\mathrm{Gd}$ is also insoluble, it will precipitate into the clayey material together with the fissile isotopes and prevent criticality. However, during the period of stainless steel corrosion, the $\mathrm{pH}$ may be lowered sufficiently that $\mathrm{Gd}$ is relatively soluble. Under these conditions the Gd will not accumulate in the clayey material. For this reason, the clayey material is 
considered the most likely location for a criticality within the waste package. The criticality calculations are based on a uniform distribution of NSE within the clay.

Several less likely variations of the final configuration were also considered. These are as follows: concentration of all $\mathrm{Pu}, \mathrm{U}$, and $\mathrm{Gd}$ in the top of the clay; concentration of all $\mathrm{Pu}$, $\mathrm{U}$, and $\mathrm{Gd}$ in the bottom of the clay; and concentration of all $\mathrm{Pu}, \mathrm{U}$, and $\mathrm{Gd}$ at one end of the WP. The first variation could conceivably occur if a large amount of the DHLW glass were to degrade and slump to, or precipitate at, the bottom of the WP before the structure of the pour canisters have collapsed. When collapse of the pour canisters does occur, this will leave the Pu containing canisters and any non-slumped DHLW glass clay, on top of the clayey material. This would result in a final configuration with an upper layer of Pu/U/Gd bearing clay and a bottom layer of clay containing little or no Pu/U/Gd. The last alternative configuration, concentration at one end, could arise from a tilting of the package due to a support failure that could cause the immobilized plutonium cans to shift to one end of the package, but the clay would also be shifted. Settling of the Pu-containing canisters to the bottom of the clay (which came from the HLW canisters) could occur while the Pucontaining canisters are still relatively intact in high-water fraction clay, or as a result of shaking during a seismic event. However, such a configuration would be much less likely to permit any flushing of $\mathrm{Gd}$, since it would be trapped under a protective layer of clayey material not containing Pu/U/Gd.

It should be noted that, with both the glass and ceramic WFs, most of the clayey material comes from the filler glass and DHLW canisters, and is essentially the same for both cases. There are, however, differences in clayey composition due to the different chemical compositions of the WFs and the much longer time to degradation for the ceramic WF. The most important of these differences neutronically is the Hf (a major neutron absorber) concentration due to the greater zirconium concentration in the ceramic WF. These different WFs also result in somewhat different mineral inventories for the clayey mass as output by the EQ6 runs. Of these ancillary differences, the one of greatest importance is the lower water of hydration in the clayey mass from the ceramic WF: equivalent of 20.7 volume percent water as contrasted with $33 \%$ for glass.

\section{Criticality Results}

A number of ${ }^{239} \mathrm{Pu}$ and ${ }^{235} \mathrm{U}$ mass combinations were run with varying amounts of water (both free and in hydration of the clayey material). For combinations of ${ }^{239} \mathrm{Pu}$ and ${ }^{235} \mathrm{U}$ requiring more than about $2.5 \mathrm{~kg} \mathrm{Gd}$ to fall below $a \mathrm{k}_{\text {eff }}$ of 0.98 , the highest value of $k_{\text {eff }}$ was found to occur at zero free water. This result shows that the water bound in clay is sufficient for criticality, without any standing free water. For combinations of ${ }^{239} \mathrm{Pu}$ and ${ }^{235} \mathrm{U}$ requiring less than about $2.5 \mathrm{~kg} \mathrm{Gd}$, the highest value of $\mathrm{k}_{\mathrm{eff}}$ was found at 0.10 or greater water fraction. Because of the approximately 0.25 $\mathrm{eV}$ resonance in the ${ }^{239} \mathrm{Pu}$ fission cross-section, the ${ }^{239} \mathrm{Pu}$ was worth significantly more than the equivalent mass of ${ }^{233} \mathrm{U}$ in the presence of $\mathrm{Gd}$. In the absence of $\mathrm{Gd}$, the ${ }^{239} \mathrm{Pu}$ is still worth more than ${ }^{235} \mathrm{U}$, but the difference in worth is not nearly so significant.

The test of sensitivity to the assumption of homogeneous distribution of the NSE started with concentrations of $\mathrm{U}, \mathrm{Pu}$, and $\mathrm{Gd}$ chosen to produce near-criticality, $\mathrm{k}_{\mathrm{eff}}=0.95$, and considered the following cases of deviation from homogeneity:

1. Concentration of the same amount of NSE in the lower $50 \%$ of the clay, which was found to increase $k_{\text {eff }}$ by 0.10 ; further concentration into the lower $25 \%$ was found to decrease $k_{\text {eff }}$ from this peak, but still leave it 0.08 higher than the homogeneous distribution.

2. Concentration of the same amount of NSE in the upper $50 \%$ of the clay which was found to increase $k_{\text {eff }}$ by 0.04 ; further concentration into the upper $25 \%$ was found to decrease $k_{\mathrm{eff}}$ by 0.10 by comparison with the original homogeneous distribution.

3. The same density of NSE in $1 / 2$ the WP length (which means $1 / 2$ the total amount of fissile material and neutron absorbers that were originally in all the WFs of the WP) only reduces $k_{\text {eff }}$ by 0.015 . This indicates that if the full mass of NSE were concentrated in $1 / 2$ the length there would be a significant $k_{\text {eff }}$ increase.

All three of these cases show that spreading the fissile material throughout the clay volume does not give the most reactive configuration, primarily because the clay contains nearly $20 \mathrm{wt} \%$ iron. By moving the NSE to half the volume, the above cases reduce the amount of iron available for neutron absorption. The first two cases (concentration in bottom or top) also show that by concentrating further to $25 \%$ of the full volume will reduce $k_{\text {eff }}$, because of the approach to the thin slab geometry that has high neutron leakage. This slab geometry is much more pronounced in the case of concentration in the upper region of the clay (case 2) than in the bottom (case 1).

It should be noted that these three non-homogeneous configurations are very unlikely because the waste form fragments will be distributed throughout the clay as they degrade, and there is little mobility of the degradation products once they are in the clay. If, however, the applicable disposal criticality regulation turns out to not allow considerations of probability, the design basis analysis may have to be the one of these cases which has the largest $k_{\text {eff. }}$ 
The mass-balance program was used to compute the amounts of NSE in solution and in the clayey precipitate as a function of time. An important input to this process is the product of the waste form dissolution rate (expressed in $\mathrm{g} / \mathrm{m}^{2} /$ day) multiplied by the fracture factor; this is called the dissolution product factor (DPF). The program incorporates a formula for $\mathrm{Gd}$ solubility as a function of $\mathrm{pH}$, which was abstracted from a number of EQ6 runs. It also incorporates the regression for $k_{\text {eff }}$ as a function of the amounts of the three NSE as extracted from the MCNP calculations for typical configurations. The program gives outputs in the following forms:

1. Screening for the values of $\mathrm{Pu}, \mathrm{U}$, and $\mathrm{Gd}$ concentration in the clayey material at which a criticality first occurs.

2. Listing the time history of $k_{\text {eff }}$.

3. A search for the minimum values of DPF, that can permit criticality.

The last of these outputs, DPF Limit, is the most relevant to design recommendations. Figure 1 shows the DPF Limit as a function of Pu loading for two drip rates ( $1 \mathrm{~mm} / \mathrm{yr}$ and 10 $\mathrm{mm} / \mathrm{yr}$ ) for the ceramic waste form. If the DPF exceeds the value indicated by the curve for the chosen value of $\mathrm{Pu}$ loading, and the assumed drip rate, the system may become critical; if the DPF is lower than the curve criticality is not possible for one of the following reasons: (1) not enough Gd has been released from the WF by the time the stainless steel has completely degraded and the $\mathrm{pH}$ returned to neutral; or (2) there is no longer enough $U$ to form a critical mass by the time of complete stainless steel degradation. It is shown in Ref. 1 that the DPF Limit curve for the glass waste form extends down to $27 \mathrm{~kg} \mathrm{Pu}$ loading, and that the curve is lower than the ceramic curve for those Pu loadings above $55 \mathrm{~kg}$ (where the ceramic curve exists). This better criticality behavior for ceramic is due primarily to the presence of approximately $2 \mathrm{wt} \% \mathrm{Hf}$ in the ceramic.

Figure 1. DPF Limit vs Pu loading (kg/pkg)

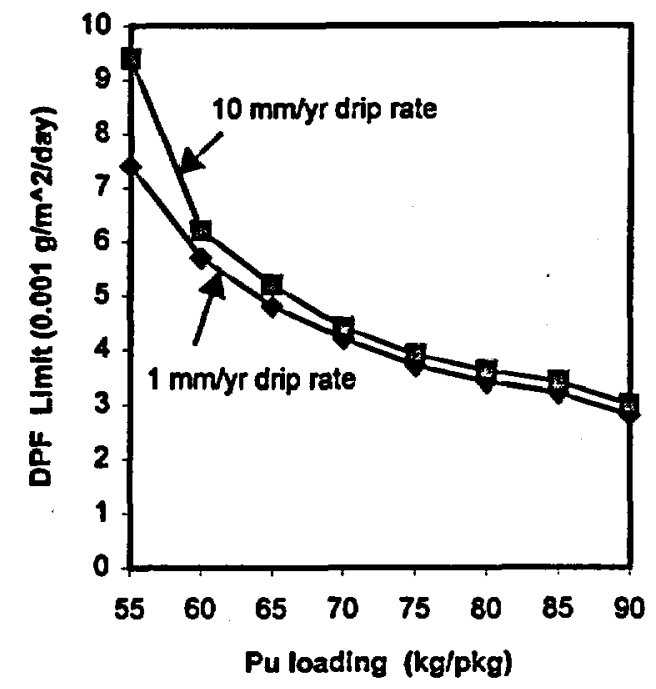

In general, the higher the DPF Limit the more robust is the criticality control design. However, this rule no longer applies if the $\mathrm{Pu}$ loading falls so low that the second reason listed in the previous paragraph applies. This is illustrated by the cutoff point on the $x$-axis of the figure, $55 \mathrm{~kg}$. Lower Pu loadings will not have enough fissile elements left for a critical mass by the time the NSE concentrations have achieved a steady state. Figure 1 also shows a higher DPF Limit for the $10 \mathrm{~mm} / \mathrm{yr}$ drip rate than for the $1 \mathrm{~mm} / \mathrm{yr}$ drip rate. There are two complementary reasons for this behavior: (1) the higher drip rate flushes more ${ }^{235} \mathrm{U}$ from the WP; (2) the higher drip rate dilutes the $\mathrm{pH}$ lowering effect of chromic acid so that $\mathrm{Gd}$ becomes less soluble.

\section{Summary of Conditions that can Lead to Criticality}

The type and quantity of neutron absorber included in the proposed immobilized Pu WFs are sufficient to prevent criticality in intact configurations, even if the WP is filled with water (highest possible concentration of moderator). For criticality to occur in, or near, a WP of immobilized Pu WF, most of the neutron absorber has to be separated from the fissile material.

A low pH (less than 6.0) may permit the principal added neutron absorber, $\mathrm{Gd}$, to have at least 1000 times the solubility of $\mathrm{U}$ or $\mathrm{Pu}$. Under moderate or high flow rates, this difference in solubility could result in so much of the Gd being removed from the WP, that there is the potential for a criticality event.

The corrosion of the stainless steel components of the WP (specifically the stainless steel of the pour canister) may result in the oxidation of $\mathrm{Cr}$ or Mo to a high-enough valence-state that the water becomes acidic. The resulting $\mathrm{pH}$ of the water in the WP depends on the rate at which the acid that is produced (if any) is flushed from the system.

If the above conditions hold during the time period of principal WF degradation, the relatively insoluble fissile material being released from the degrading WF may precipitate in a clay mass which could contain sufficient water to moderate a criticality.

If all of the above conditions hold, the earliest time of criticality occurrence is typically 100,000 years; under certain "worst case" conditions, the earliest time to criticality could be as low as 12,000 years. 


\section{Summary of Conditions Precluding the Processes which can Lead to Criticality}

The following conditions will tend to prevent the occurrence of the conditions that can lead to criticality (listed above):

The acidity produced by the corroding stainless steel may be neutralized by the alkalinity of the incoming water (which may be maintained at a high $\mathrm{pH}$ by remnants of the concrete drift liner).

Certain elements present in the WP may form precipitates of Gd that have not yet been identified in the chemical literature. Such precipitates could limit the solubility of $\mathrm{Gd}$, even at low $\mathrm{pH}$. One such compound which the literature indicates should have a low solubility is $\mathrm{GdPO}_{4}$. Even if there are conditions that lead to high Gd solubility, there may be sufficient penetration of the package bottom that the fissile material does not precipitate in a compact cylinder sector at the bottom of the WP.

\section{Design Guidance}

For the waste forms and degradation modes considered here, it is possible to preclude the possibility of criticality by maintaining a plutonium loading limit, which should be controlled according to the appropriate DPF Limit curve, such as the one shown in Figure 1.

Since the presence of hafnium is shown to increase this loading limit, the defense-in-depth policy would suggest the maximization of the amount of Hf as a backup criticality control material.

At the end of 1997, after this study was completed, the ceramic waste form was downselected and a new formulation was developed, with the amount of Hf increased to the point where internal criticality may no longer be possible. The new ceramic formulation was in agreement with the design recommendations of Ref. 1, particularly in the following respects: (1) reducing the $\mathrm{Pu}$ content from 51 to $28 \mathrm{~kg}$ per pour canister; (2) increasing the amount of $\mathrm{Hf}$, (3) designing a ceramic formulation which would be less likely to metamict. With the additional criticality control provided by these features, it is possible that the number of Pu bearing canisters can be increased to 4 or 5 per waste package.

As guidance for future design decisions, it should be noted that, recent calculations (Ref. 4) indicate that $\mathrm{GdPO}_{4}$ is insoluble over a much broader range of $\mathrm{pH}$ than is $\mathrm{Gd}_{2} \mathrm{O}_{3}$, so that its use as the Gd carrier in the waste form would provide an extra margin of defense-in-depth.

\section{Acknowledgement}

This work was supported by the U. S. Department of Energy, Yucca Mountain Site Characterization Office as part of the Civilian Radioactive Waste Management Program.

\section{References}

1. Degraded Mode Criticality Analysis of Immobilized Plutonium Waste Forms in a Geologic Repository, DI\#: A00000000-01717-5705-00060 REV 01, CRWMS M\&O, February 1997.

2. Davis, J.W. and P. Gottlieb, Disposal Criticality Analysis of Fissile Waste Forms, this conference proceedings.

3. Wolery, T. J., EQ3/6, A Software Package for Geochemical Modeling of Aqueous Systems: Package Overview and Installation Guide (Version 7), UCRL-MA-1 10662 PT I, September 1992.

4. Evaluation of Codisposal Viability for AluminumClad DOE-Owned Spent Fuel: Phase II Degraded Codisposal Waste Package Internal Criticality, DI\#: BBA000000-01717-5705-0017 REV 01, April 1998. 